\title{
BIOPOLÍTICA, INDÚSTRIA FARMACÊUTICA E MEDICALIZAÇÃO: CONSTRUÇÕES DE FORMAS SIMBÓLICAS SOBRE A INFLUENZA A(H1N1)
}

Guilherme Corrêa Adriane Roso $\star \star$

\section{RESUMO}

A presente pesquisa teve como objetivo analisar como a biopolitica perpassa os discursos midiáticos de um jornal de circulação na região central do estado do Rio Grande do Sul sobre Gripe A (H1N1), buscando tornar visivel como as práticas institucionais e discursivas atravessam e constituem os sujeitos. Neste estudo apresentamos a parte da pesquisa que se refere aos desdobramentos da biopolítica referentes à indústria farmacêutica e medicalização. Sob uma perspectiva cartográfica, foram analisadas um total de 291 reportagens veiculadas durante o mês de julho de 2009. Como resultado da pesquisa, podese observar a influência que as mídias de massa e as elites simbólicas exercem sobre os sujeitos devido às construções de material simbólico, que acabam por surtir efeito não só nos corpos dos sujeitos, mas nas dinâmicas das populações.

Palavras-chave: meios de comunicação impressos; psicologia social; influenza humana A (H1N1);

\section{BIOPOLITICS, PHARMACEUTICALS AND MEDICALIZATION: CONSTRUCTION OF SYMBOLIC FORMS OF THE INFLUENZA A (H1N1)}

\section{ABSTRACT}

This study aimed to analyze how biopolitics encompasses the media discourse in a newspaper circulating in the central region of Rio Grande do Sul on Influenza A (H1N1), seeking to make visible the practices and discursive institutions and are cross the subjects. This study presents the part of the research refers to the ramifications of biopolitics regarding pharmaceuticals and medicalization. From a cartographic perspective, we analyzed a total of 291 articles published during the month of July 2009. As a result of research, can observe the influence of mass media and the symbolic elites have on the subject due to the constructions of symbolic material, which ultimately have an effect not only on the bodies of the subjects, but the dynamics of populations.

\footnotetext{
^ Psicólogo. Mestrado em Psicologia pela Universidade Federal de Santa Maria. Atualmente é professor do Centro Universitário Franciscano. Endereço: Av. Roraima n ${ }^{\circ} 1000$ - Cidade Universitária - Bairro Camobi - Santa Maria - RS.

E-mail: guicor1978@gmail.com

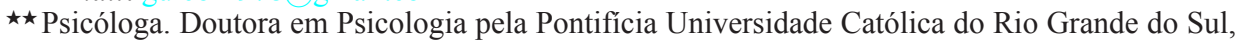
Professora Adjunta da Universidade Federal de Santa Maria. Endereço: Universidade Federal de Santa Maria, Centro de Ciências Sociais e Humanas. Rua Marechal Floriano Peixoto 1750/321. Centro - Santa Maria, RS - Brasil.

E-mail: adrianeroso@gmail.com
} 
Keywords: social psychology; influenza A (H1N1); printed communications media.

\section{INTRODUÇÃO}

As doenças e pestes sempre povoaram o imaginário das populações, seja por suas causas misteriosas ou pelas possibilidades de grandes danos à sociedade. As doenças assombraram a imaginação de inúmeros povos em diferentes períodos históricos, a Baixa Idade Média, donde visões aterradoras do inferno e do diabo, dos cavaleiros do apocalipse e da tão temida figura da morte empunhando sua foice, traziam medo ao coração dos homens que acreditavam na ira divina sobre estes (PORTER, 2004). Nos últimos anos, termos como "Gripe Suína", "Influenza A", "Gripe A" (H1N1) e "Pandemia", foram usados ativamente pela mídia nacional e internacional, e provocaram agitação e comoção social. A gripe A (H1N1) estrelou nos principais meios de comunicação, tais como as pandemias anteriores, como uma nova doença capaz de causar um número de mortes sem precedentes. Entretanto, o que não foi divulgado pela mídia, mas já era de conhecimento dos pesquisadores das áreas da infectologia, epidemiologia, dentre outras, é que esta cepa já circulava pelo mundo desde antes de Cristo. Famosa desde o episódio da gripe espanhola de 1918, nunca deixou de circular pelo planeta durante o último século (KOCH, 2005; GOLONO, 2004; SÁ, 2002; SOUZA, 2007; KAWAMOTO, 1999; TOLEDO JUNIOR; COSTA, 2006; PORTER, 2004; ABRÃO, 2009; UJVARI, 2003). Segundo Potter (2001), as epidemias e pandemias podem ser rastreadas historicamente com precisão moderada (até pelo menos 300 anos), e os padrões de surtos revelam acontecimentos entre períodos de 10 e 50 anos, ou seja, a humanidade esteve em contato frequente com esta cepa e suas variantes no decorrer do último século.

Caminhando juntamente com os eventos históricos que denunciam a constante ação do vírus da influenza, encontramos a ação, em 1952, da Organização Mundial de Saúde. A OMS estabeleceu a Rede Global de Vigilância da Influenza, composta por quatro centros de pesquisa colaboradores (Austrália, Japão, Estados Unidos e Reino Unido), além de outros 112 centros de pesquisa, distribuídos em 83 países, incluindo o Brasil. A Rede Global de Vigilância da Influenza é responsável por isolar e caracterizar anualmente os vírus em circulação, podendo assim tomar as medidas necessárias para conter possíveis epidemias e pandemias, desenvolvendo vacinas e colocando em alerta todos os profissionais da área da saúde (TOLEDO JUNIOR; COSTA, 2006).

Embora seja um evento bastante recente, a relação entre Gripe A (H1N1), mídia e biopolítica parece ainda ter sido pouco explorada no campo da pesquisa acadêmica. Em pesquisa sistemática realizada recentemente no Portal de Teses e Dissertações da CAPES (CORRÊA; ROSO, 2010), constatou-se que, na área da psicologia, não estão disponibilizados trabalhos relacionados à temática em questão, enquanto no jornalismo, por exemplo, consta apenas uma publicação no portal de teses e dissertações da CAPES que faz conexão entre as ciências sociais e 
a gripe A (H1N1) (SERRA, 2009). Isso mostra a importância e relevância, para o campo das ciências sociais e humanas, especialmente na psicologia, de uma pesquisa que intenta explorar os discursos produzidos em relação a uma pandemia.

Nesse contexto, o trabalho do psicólogo na saúde pública, mais especificamente no viés da psicologia da saúde, é de grande importância, pois a psicologia da saúde centra-se nos determinantes, nos mediatizadores e nas consequências dos comportamentos das pessoas e em suas inter-relações (MATOS, 2004). As intervenções devem ser realizadas tanto sobre os fatores de risco como nos fatores de proteção. Em termos de práticas, além de atuar na recuperação de doenças, o psicólogo da saúde pode intervir em campanhas de conscientização e esclarecimentos de cunho preventivo (prevenção primária), no planejamento e execução de ações que envolvam a promoção da saúde e/ou a resolução de problemas da comunidade (LIMA, 2005). O campo de atuação do psicólogo da saúde centra-se em serviços de atenção primária (promoção e prevenção de saúde), na atenção à comunidade, aonde são considerados fatores históricos, sociais e culturais, além dos individuais envolvidos nos processos de saúde-doença (TEIXEIRA, 2004).

No caso de episódios como o da pandemia da Gripe A (H1N1), o trabalho do psicólogo da saúde se faz fundamental no âmbito da saúde pública, pois muitas vezes, as práticas de prevenção não são suficientemente esclarecidas para a população, deixando margem para entendimentos fantasiosos. Por este motivo, recorremos à perspectiva da Psicologia Social Crítica da Saúde, que, segundo Roso (2007) tem como premissa a dialogicidade com os sujeitos e o respeito aos saberes populares, analisando as relações de poder e a ética do cuidado.

Levando isso em conta, a pesquisa realizada teve como foco o município de Santa Maria, Rio Grande do Sul, Brasil. Dentre as características marcantes da cidade, tais como a religiosidade, militarismo e a presença de várias instituições de ensino superior, uma se destaca aos olhares mais atentos: sempre que se alerta a população sobre uma possível epidemia, ou pandemia, as pessoas formam filas imensas em frente aos postos de saúde para que sejam atendidas o mais rápido possível, como foi ocaso da Febre Amarela e da Gripe A (H1N1). Talvez se possa pensar que estes sujeitos estejam muito preocupados com as questões de saúde pública, mas, por outro lado, este comportamento também leva a refletir sobre como estas pessoas estão elaborando a quantidade maciça de informações que recebem da mídia (local, regional e nacional) sobre a pandemia.

Além das filas presenciadas nos postos, também pudemos observar uma busca incessante da população por produtos que garantissem sua saúde. O medo do contágio resultou que nas farmácias e colégios ficou cada vez mais difícil, por exemplo, encontrar álcool gel, tamanha a demanda. Esse medo quase que generalizado de "pegar" a gripe foi capturado pela mídia local, como pudemos observar a partir da produção de diversas matérias sobre o tema. Através do processo de "midiação da cultura moderna", salienta Thompson (1995), formas simbólicas (ações e falas, imagens e textos) mercantilizadas se tornam acessíveis a um grupo cada vez maior de receptores e a: 
Compreensão desse processo é fundamental para se entender o mundo de hoje, um mundo que é sempre mais atravessado por redes institucionalizadas de comunicação e em que as experiências das pessoas está cada vez mais mediada por sistemas técnicos de produção e transmissão simbólica", tais como a televisão (THOMPSON, 1995, p. 21).

Tendo como premissa essa perspectiva de análise das mídias, podemos ter uma noção do alcance das informações relacionadas à pandemia da gripe $\mathrm{A}$ (H1N1), já que esta foi veiculada por diferentes aparatos comunicacionais, tais como televisão, rádio, mídia escrita e internet. Nos dias de hoje, a mídia possui um grande poder de influência na vida dos sujeitos. Obviamente não vemos as pessoas como incapazes de refletir sobre o que lhes é ofertado, mas temos que levar em consideração o quanto a mídia pode ser sugestiva. Pensando nesta problemática, e envolvidos pelos pressupostos da Psicologia Social Crítica, nos é impossível fazer "vistas grossas" sobre uma questão que afeta a vida das pessoas. Como Teun Van Dijk (2008) declara, as pesquisas podem e devem ter cunho crítico e existem referenciais teóricos sólidos para fazê-lo.

Nesse sentido, pretendemos enfocar os discursos midiáticos online produzidos por um jornal de circulação, que atinge a cidade de Santa Maria e cidades circunvizinhas. Se pretende trazer "luz" sobre como as informações são construídas e transmitidas à população, e sobre como formas de relações de poder, mais especificamente biopoder, podem fazer disparar/funcionar tanto os discursos dos operadores de dominação quanto os discursos do cotidiano (saberes locais) em relação à saúde, ao corpo, à vida das pessoas. Ou, como sugeriu Foucault (2005, p. 32), "Trata-se de apreender, ao contrário, o poder em suas extremidades, em seus últimos lineamentos, onde ele se torna capilar; ou seja, tomar o poder em suas formas e em suas instituições mais regionais, mais locais".

O presente trabalho deriva da pesquisa de mestrado intitulada "Biopolítica, gripe A (H1N1) e mídia: o que pode um porco?". Esse título não foi escolhido ao acaso. Pensando em toda a atenção que a mídia despendeu para o evento da gripe A (H1N1) e principalmente para a culpabilização dos suínos, foi impossível não fazer um trocadilho de inspiração em Espinoza: de "O que pode um corpo? para O que pode um porco?" Quando se trata de biopolítica, o corpo e a saúde das populações são premissas básicas para o entendimento das dinâmicas do poder, inseridas cuidadosamente nos discursos, para que o corpo seja normatizado (CORRÊA, 2012).

O objetivo da pesquisa foi analisar como a biopolítica perpassa os discursos midiáticos de um jornal de circulação na região central do estado do Rio Grande do Sul sobre Gripe A (H1N1), buscando tornar visível como as práticas institucionais e discursivas atravessam e constituem os sujeitos. Como objetivos específicos, visou identificar, nas formas simbólicas do jornal, os modos pelos quais a saúde da população pode se tornar alvo de um poder sobre a vida; reco- 
nhecer os diferentes elementos de disciplinarização dos corpos ressaltados nas formas simbólicas e averiguar elementos discursivos presentes nas formas simbólicas que podem estar contribuindo para se fazer viver as biotecnologias.

No presente estudo apresentamos a parte da pesquisa que se refere aos desdobramentos da biopolítica referentes à indústria farmacêutica e medicalização. A discussão apresentada buscou refletir sobre a seguinte questão: como a otimização da qualidade biológica das populações se expressa nas formas simbólicas do jornal? Que espécie de elementos discursivos presentes nas formas simbólicas podem contribuir para se fazer viver as biotecnologias?

O conceito de biopolítica é entendido aqui como o termo forjado por Foucault (1995) para designar formas de exercício de poder sobre a vida. A biopolítica se centra nos mecanismos do ser vivo e nos processos biológicos, tendo como objeto a população, designando a entrada do corpo e da vida, bem como de seus mecanismos, no domínio dos cálculos do poder, fazendo do poder-saber um agente de transformação da vida humana (PELBART, 2003). Portanto, esta pesquisa pretende elucidar questões sobre como as informações são construídas e transmitidas à população enquanto formas de manipulação que se inserem nos discursos do cotidiano, isto é, como as informações são transmitidas, distorcidas ou hiper-dimensionadas pela mídia.

Por manipulação entende-se como:

uma das práticas sociais discursivas de grupos dominantes que servem à reprodução do seu poder. Esses grupos dominantes podem fazer isso também de várias (outras) formas, por exemplo, através da persuasão, fornecendo informações, educação, instrução e outras práticas sociais que objetivam influenciar o conhecimento, as crenças e (indiretamente) as ações dos receptores (DIJK, 2008, p. 237).

O conceito de manipulação pode levar à ideia errônea de que se pretende posicionar a mídia no papel de grande vilã. A manipulação é um elemento, dentre outros, a ser olhado com atenção pelos analistas políticos. Assim, ao assinalar a manipulação presente em discursos públicos não nos posicionamos contra a vacina para a gripe A (H1N1) e nem contra as mídias de massa. O que se quer é levantar a problematização sobre como as questões do Estado, mídia e indústria farmacêutica estão entrelaçadas. Este entrelaçamento pode produzir e modificar as políticas de promoção da saúde e é justamente aí que a atenção do psicólogo da saúde e de cientistas sociais precisa se voltar: mostrar como a biopolítica presente nos discursos midiáticos pode engendrar "uma compreensão mais ampliada do processo saúde-doença".

\section{Pressupostos ePISTEMOLÓGicos E METOdOLOGIA}

A pesquisa foi realizada tendo como base teórica os pressupostos da Psicologia Social Crítica. A Psicologia Social Crítica da Saúde origina-se da Psicologia Social Crítica. Propondo-se a superar a perspectiva adaptacionista e comporta- 
mentalista da Psicologia Social tradicional advinda, principalmente, da Psicologia Social Norte-americana, a Psicologia Social Crítica, e por extensão a Psicologia Social Crítica da Saúde, adota uma posição ético-reflexiva em relação aos seus compromissos sociais e políticos que, por sua vez, objetiva a complexificação do simples e a diversidade teórica e metodológica, fazendo uma interlocução entre as diferentes áreas da psicologia (STREY, 2005).

Por se tratar de um recorte de uma pesquisa maior, o processo de construção genealógica proposto originalmente não fica explicito. Entretanto a metodologia genealógica será desenvolvida a seguir a fim de esclarecer o processo da pesquisa como um todo. Para este recorte, optamos por usar o processo cartográfico como uma forma de experimentação metodológica, pois como afirmam Passos, Kastrup e Escócia (2009, p. 10, grifo do autor):

A cartografia propõe uma reversão metodológica: transformar o metá-hódos em hódos-metá. Essa reversão consiste numa aposta na experimentação do pensamento - um método não para ser aplicado, mas para ser experimentado e assumido como atitude. Com isso não se abre mão do rigor, mas este é ressignificado.

Para além da cartografia, realizou-se na pesquisa o que Rose (2007) determina de cartografia do presente, uma forma de analisar o presente e pensar em futuros potenciais. Traçando caminhos heterogêneos que levam a uma aparente solidez do presente, historicisando aspectos que muitas vezes são deixados de fora da história, mostrando a construção do presente, é possível fazer uma abertura para possíveis reestruturações. Intervir no presente é uma possibilidade de criar algo novo no futuro, uma possibilidade de fazer uma micropolítica (ROSE, 2007).

A proposta da genealogia histórica, ${ }^{1}$ como proposta por Michel Foucault, vai ao encontro dos propósitos da Psicologia Social Crítica da Saúde. Nela, conforme Bauer e Gaskel (2003), o trabalho do pesquisador se volta para a construção histórica dos discursos, e não somente para a análise de textos falados ou escritos e visa o aprofundamento da análise através do entendimento das condições que possibilitam o surgimento e permanências das práticas discursivas. Dentro dessa perspectiva é possível compreender as formações discursivas como uma construção histórica, que produzem ou permitem a emergência dessas como dispositivos de poder. O método não tem como fundamento desmantelar os sujeitos, analisando o passado em busca de uma nova verdade, e sim busca uma análise do que os sujeitos são, enquanto atravessados pela vontade de verdade, fazendo um estudo das formas de poder (FAE, 2004). O que se pretende é estabelecer relações entre os saberes, sem fazer julgamentos hierárquicos sobre estes, e sim aceitá-los como tal, da forma como foram concebidos, para que destas relações surjam compatibilidades e incompatibilidades que possibilitem a individualização das formações discursivas. (MACHADO, 1995). 
Na genealogia buscamos "escutar" nas formas simbólicas veiculadas pelo jornal as táticas ligadas aos "saberes sujeitados" - "toda uma série de saberes que estavam desqualificados como saberes não conceituais, como saberes insuficientemente elaborados: saberes ingênuos, saberes hierarquicamente inferiores, saberes abaixo do nível do conhecimento ou da cientificidade requeridos" (FOUCAULT, 2005, p.11). Na execução desse processo é indispensável demorar-se sobre a pesquisa, podendo assim marcar a singularidade dos acontecimentos, diferentemente de uma forma estática de fatos apenas listados, extrair os sentidos daquilo que é considerado como não possuindo história, contextualizando politicamente os eventos. Apreender o retorno dos acontecimentos é importante não apenas para traçar uma curva evolutiva, mas para demonstrar as diferentes cenas em que estes se inserem e suas prováveis lacunas (FOUCAULT, 1995).

O procedimento para a coleta das reportagens a serem analisadas ocorreu da seguinte forma: primeiramente foi usado o descritor H1N1 na guia de buscas do jornal Diário de Santa Maria na sua versão online para que as reportagens fossem localizadas no site. Delimitou-se como recorte de tempo todo o mês de julho de 2009, período este considerado o mais crítico da pandemia em função do maior número de mortes registradas. O segundo passo foi identificar e catalogar as reportagens sobre a temática em questão, dando ênfase para as reportagens que tinham relação com a cidade de Santa Maria.

Ressaltamos que ao se fazer uma análise de discurso via genealogia, a quantidade de material a ser analisado não é o ponto mais relevante, mas, sim, a qualidade e profundidade da análise. Olhando às partes de um todo jornalístico, queremos ver "o que se pode fazer com esses fragmentos" [reportagens, discursos]. Se sentir "um pouco como um cachalote que salta por cima da superfície da água, deixando nela um pequeno rastro provisório de espuma, e que deixa acreditar, faz acreditar, ou quer acreditar, ou talvez ele acredite efetivamente, que em baixo, onde não o vemos mais, onde não é mais percebido nem controlado por ninguém, ele segue uma trajetória profunda, coerente, refletida" (FOUCAULT, 2005, p. 7).

\section{RESUltados E DISCUSSÕES: FAZENDO VIVER AS BIOTECNOLOGIAS: INDÚSTRIA} FARMACÊUTICA E MEDICALIZAÇÃO

Durante o período da pandemia de gripe A (H1N1) não só as campanhas de vacinação estiveram muito presentes na mídia, mas vários produtos ligados à indústria farmacêutica, em especial o álcool gel e as mascaras cirúrgicas, aconselhados como tendo uso preventivo, até o medicamento que se tornou mundialmente famoso, especialmente por sua escassez e resultados controversos: o Tamifluß ${ }^{2}$

Na segunda-feira, alguns pais ligaram para o Diário informando que nas escolas de seus filhos, sabão, sabonete líquido e o requisitado álcool gel não estavam à disposição dos estudantes. [...]. A diretora explica que nos dois primeiros dias de aula, não foi possível contemplar todas as 15 salas com o álcool gel porque o fornecedor do material não deu conta da demanda. [...] (PORCIÚNCULA, 2009, online) 
Ortega (2003, p. 64) nos lembra que as

práticas ascéticas implicam processos de subjetivação. As modernas asceses corporais, as bioasceses, reproduzem no foco subjetivo as regras da biossociabilidade, enfatizando-se os procedimentos de cuidados corporais, médicos, higiênicos e estéticos na construção das identidades pessoais, das bioidentidades. Trata-se da formação de um sujeito que se autocontrola, autovigia e autogoverna.

O termo biossociabilidade foi cunhado por Paul Rabinow (1996), o primeiro teórico a reconhecer este fenômeno, que se caracteriza pelas novas formas de identificação coletiva que tomam forma na chamada "Era do Genoma". As pesquisas de Rabinow o levaram a identificar novos tipos de grupos e identidades individuais ligadas a praticas de técnicas de diagnóstico e monitoramento de risco e suscetibilidade a determinadas doenças e condições. Tais grupos relacionam-se para dividir experiências, arrecadar fundos para custear experiências de "suas" doenças (ROSE, 2007). Trazendo outro ponto a ser discutido, Henz (2009) caracteriza as biossociabilidades como formas corrompidas de sociabilidades, por estas estarem intimamente ligadas aos avanços biotecnológicos e, portanto, a uma leitura "biologicista" da vida, descartando, muitas vezes, "valores superiores e metafísicos" em troca de uma aposta na interioridade biológica do ser (HENZ, 2009, p 151). Henz (2009) adverte que esta crença nas bioidentidades, algo que remete ao impessoal, possa interferir na produção de subjetividades, no sentido de que a forma-homem esteja demasiadamente ligada a questões de mercado.

A preocupação de Rabinow (1996), entretanto, parece estar ligada a uma mudança de paradigma, de uma sociobiologia para uma biossociedade. Nas palavras do autor:

No futuro, a nova genética deixará de seruma metáfora biológica para a moderna sociedade e vai se tornar em vez de uma rede de circulação de termos de identidade e loci de restrição, em torno do qual e através do qual um tipo verdadeiramente novo de autoprodução vai surgir, que eu chamo "biossocialidade". Se a sociobiologia é cultura construída sobre a base de uma metáfora da natureza, então na natureza a biossocialidade será modelada na cultura compreendida como prática. A natureza será conhecida e refeita através da técnica e, finalmente, se tornará artificial, assim como a cultura torna-se natural (RABINOW, 1996. p 99).

Atualmente, o poder do mercado farmacêutico é indiscutível, estando este sempre oscilando entre o $1^{\circ}$ e $4^{\circ}$ lugar no ranking mundial das indústrias que mais faturam no mundo, ficando atrás apenas dos grandes bancos internacionais. Estes números se tornam preocupantes quando as próprias indústrias são as patrocinadoras dos estudos e seus pesquisadores e médicos são os responsáveis pela divulgação dos resultados positivos obtidos (GARRAFA; LORENZO, 2010). 
As campanhas de vacinação no Brasil foram responsáveis pela imunização de 81 milhões de pessoas para o caso da gripe A (H1N1) (IMUNIZAÇÃO..., 17 jun. 2010, online), enquanto que a comercialização de medicamentos como o Tamiflu ${ }^{\circledR}$ foram maciças, não só no Brasil, mas no mundo todo. $\mathrm{O}$ atual desenvolvimento da indústria farmacêutica foi fruto do movimento de medicalização iniciado no momento em que a biopolítica toma forma e os saberes médicos começam a incidir fortemente sobre os corpos. Entretanto, as indústrias farmacêuticas conseguiram abarcar estes saberes, como visto anteriormente.

A discussão anterior sobre biossociabilidades e produção de subjetividades torna-se mais clara quando analisada sob o ponto de vista do consumo de produtos de desejo, tais como automóveis, itens parecidos com os que são usados por celebridades, dentre outros. Mas quando se trata de otimização do corpo humano e, especialmente neste caso, sobre otimização da saúde, estes desejos podem passar despercebidos. A questão referente à medicalização, vista pela ótica da otimização, faz com que os sujeitos busquem não somente formas hiperpreventivas para cuidar de sua saúde, mas formas de assegurar o melhor futuro possível para suas vidas biológicas. Sendo assim, experimentando-se como criaturas biológicas, os sujeitos tornam-se foco de um governamento que se baseia na exploração bioeconômica, uma política exercida em nível molecular (ROSE, 2007).

$$
\text { 24/07/2009 | } \mathrm{N}^{\circ} 2245 \text { Alerta }
$$

\section{GRIPE A}

\section{A polêmica compra do Tamiflu}

Muitos gaúchos estão cruzando a fronteira com o Uruguai para comprar o Tamiflu, já que a venda do antiviral é proibida nas farmácias brasileiras pelo Ministério da Saúde. Foi o caso de uma funcionária pública de São Gabriel, que comprou cinco caixas do medicamento em Rivera, no Uruguai, por R\$ 160 cada, sem receita médica. Ela contou à reportagem da RBS TV/São Gabriel que comprou o medicamento para "proteger a família" porque a cidade tem um caso de morte suspeita pela nova gripe. O governo brasileiro compra todo o estoque do medicamento do laboratório Roche, o único que produz o remédio no mundo. Ontem, o secretário Estadual de Saúde, Osmar Terra, explicou como funciona o sistema de compra. Todo o estoque do laboratório foi vendido, não só para o Brasil, mas para outros países onde há casos da doença. Até o que o laboratório ainda não produziu já está comprado (A POLÊMICA..., 24 jul. 2009, online).

Comprar medicamento tendo um caso de morte suspeita apenas, comprar todo o estoque de medicação, inclusive o que ainda não se produziu, são medidas que se emparelham à noção de hiperprevenção, que, por sua vez, nos diz também da medicalização. 
A medicalização é considerada um novo exercício de poder, tendo suas origens no final do século XVIII, onde o saber médico ditava as normas sobre o corpo dos sujeitos, em uma distinção permanente entre o normal e o patológico (CASTRO, 2009). O conceito de medicalização é da autoria de Ivan Illich, e foi usado para descrever a inserção da medicina em todas as etapas da vida humana, desde o nascimento até a velhice, abarcando os mais variados fenômenos (SINGER; CAMPOS; OLIVEIRA, 1988). Mas embora a medicina tenha desempenhado um papel de grande importância na normatização das questões referentes ao corpo, nos dias de hoje vemos a indústria farmacêutica tomando conta da produção destes saberes e usando-os em prol de uma comercialização massiva de remédios.

A produção do conhecimento médico, que resulta das pesquisas, é de caráter puramente comercial. Segundo Camargo Jr. (2010), as distorções cometidas para a aprovação de novos medicamentos contam com estratégias tais como, distorções de dados para obtenção de resultados favoráveis, uso de figuras-chave da medicina para endossar novas drogas, produção de artigos científicos escritos por ghost writers ${ }^{3}$ e assinados por pesquisadores supostamente respeitáveis e as conhecidas distribuições de presentes para os médicos.

Mas um fator importante que o autor citado salienta é sobre a importância das revistas científicas impressas por seu grau de confiabilidade, já que os artigos produzidos são publicados em revistas internacionais com alto fator de impacto (CAMARGO JR., 2010). O que é publicado nas revistas científicas de renome internacional é rapidamente capturado pelas mídias de massa e amplamente divulgado, como podemos confirmar nas manchetes abaixo:

Revistas Science e Nature avaliam publicar estudo sobre vírus mortal (REVISTAS Science..., 20 dez. 2011, online)

Revistas avaliam como publicar estudo sobre vírus mortal de forma que detalhes não caiam em "mãos erradas". Especialistas pediram que publicações omitissem dados da metodologia da pesquisa, sob o argumento de proteger a população de possíveis atos terroristas. [...]. Duas grandes revistas científicas, a americana Science e a britânica Nature, anunciaram nessa terça-feira que estão avaliando a forma mais adequada de publicar um estudo sobre um vírus mortal mutante da gripe (REVISTAS avaliam..., 21 dez. 2011, online).

Esta lógica de produção de saberes legitimados vai ao encontro daquilo que Foucault (1995) chamou de saber-poder e as reportagens a seguir evidenciam a ligação entre as figuras representantes deste saber e o mercado mundial de medicamentos. 


\section{Geral | 16/07/2009 21h40min}

Obama reserva US\$ 1,8 bilhão para o combate à gripe $\mathrm{A}$

O presidente dos Estados Unidos, Barack Obama, decidiu hoje usar US\$ 1,825 bilhão de um fundo criado pelo Congresso para agilizar os planos de prevenção a um eventual aumento no número de casos da gripe suína durante no fim do ano. O dinheiro será usado na compra de remédios que potencializem os efeitos da futura vacina contra a gripe, na aprovação desta pelo FDA (agência reguladora do setor de alimentos e medicamentos) e numa campanha de imunização (OBAMA..., 16 jul. 2009, online).

\section{Geral 17/07/2009 09h47min}

Gripe: governo negocia compra de vacina, diz secretário

O secretário de Ciência, Tecnologia e Insumos Estratégicos do Ministério da Saúde, Reinaldo Guimarães, afirmou que o governo federal iniciou negociações com empresas que desenvolvem vacina para gripe $\mathrm{A}(\mathrm{H} 1 \mathrm{~N} 1)$, a chamada gripe suína. Guimarães contou que o desenvolvimento da vacina contra a influenza A (H1N1) esbarra em dois problemas. O primeiro deles é a capacidade dos fabricantes em abastecer o mercado: - Já há um convencimento de que não haverá vacinas para todos no mundo. O segundo está relacionado à dificuldade no seu desenvolvimento: a vacina contra a gripe A tem rendimento menor do que a da gripe comum nos laboratórios, o que pode atrasar o cronograma para a entrega. - As informações são do jornal O Estado de S. Paulo (GRIPE..., 17 jul. 2009, online).

Por serem fruto deste tipo de produção de saber, alguns medicamentos são considerados, assim como as famosas produções hollywoodianas, como blockbusters, devido ao tamanho de seu sucesso comercial. Entretanto, a aceleração dos processos de comercialização globalizada de medicamentos nas últimas décadas, criou uma série de problemas éticos, tais como vulnerabilidade social em países periféricos que servem muitas vezes de "campos de testes" para novos fármacos por possuírem leis mais flexíveis, afetando desta forma a Declaração de Helsinque (WMA, Oct. 2008, online), documento internacional elaborado pela Associação Médica Mundial, que visa regular as normativas de ética em pesquisa com seres humanos (GARRAFA; LORENZO, 2010). Porém, a validade da Declaração de Helsinque não só é questionada, como também é ignorada, como é no caso dos Estados Unidos, país que abandonou e ignora os preceitos do documento (GARRAFA; LORENZO, 2010). Além disso, este tipo de ação, vindo especialmente do país que controla as maiores empresas farmacêuticas do mundo, 
inclusive a Gilead Sciences, detentora da patente do Tamiflu ${ }^{\circledR}$ e anteriormente presidida por Donald Rumsfeld (DONALD..., 3 jan. 1997, online), ex-secretário de defesa dos Estados Unidos, é bastante controverso.

O monopólio de determinado país sobre as indústrias farmacêuticas é um ponto importante na questão, mas preferimos, por ora, enfocar como as testagens da medicação, e aqui falamos da vacina para a gripe A (H1N1), foram conduzidas, não considerando o tempo mínimo de segurança. Segundo o Ministro da Saúde, José Gomes Temporão, o prazo seguro para a produção da vacina é de aproximadamente um ano, pois esta precisaria de ao menos quatro a seis meses antes de poder ser testada em humanos para averiguar possíveis efeitos colaterais. O prazo previsto para a elaboração segura da vacina seria o inicio do segundo semestre de 2010 (LOPES, 28 jul. 2009, online).

As reportagens abaixo deixam transparecer a preocupação das autoridades da OMS sobre o desenvolvimento da vacina e a pressa do governo britânico em disponibilizar uma vacina contra a Gripe A.

Geral | 15/07/2009 11h33min

OMS estima que vacina contra a gripe vai demorar meses para estar disponível

A diretora-geral da Organização Mundial da Saúde (OMS), Margaret Chan, disse que a vacina contra a gripe A estará disponível apenas daqui a alguns meses, já que não há garantias de que as primeiras doses sejam seguras. Não há uma vacina. Ela deveria estar disponível em breve, em agosto. Mas ter uma vacina disponível não é a mesma coisa do que ter uma que tenha resultados seguros. O The Guardian diz que o governo do Reino Unido pediu em junho a duas companhias farmacêuticas o rápido desenvolvimento da vacina, mas os testes preliminares das doses começaram há apenas duas semanas (OMS..., 15 jul. 2009, online).

O que percebemos aqui é a diferença entre dois discursos: um de um órgão internacional governamental (OMS) e outro bem contextual (governo britânico). Enquanto o discurso da OMS nos remete à cautela, indicando preocupação em relação ao processo de testagem, o discurso do governo britânico nos remete à pressa.

Embora a OMS, o principal órgão regulador das questões de saúde pública no mundo, peça cautela no desenvolvimento da vacina, alguns países, como a Inglaterra, adotam medidas preventivas que vão contra as recomendações da OMS, como na reportagem a seguir: 


\section{Geral | 22/07/2009 09h55min}

Grupo farmacêutico britânico começará a distribuir vacina da gripe no segundo semestre

O gigante farmacêutico britânico GlaxoSmithKline (GSK) afirmou hoje que começará o envio dos 195 milhões de doses da vacina contra a nova gripe a partir do segundo semestre deste ano. $\mathrm{O}$ investimento será de 2 bilhões de libras (2,312 bilhões de euros) para a pesquisa e desenvolvimento desta vacina, assim como para ampliar a produção do antiviral Relenza, cuja demanda aumentou consideravelmente à medida em que a doença se expande. Neste sentido, a GSK afirmou que, no final deste ano, a capacidade de produção deste remédio será triplicada, até 190 milhões de caixas. A Glaxo faz parte do grupo de 30 laboratórios encarregados de fabricar a vacina contra uma pandemia. (GRUPO..., 22 jul. 2009, online)

Pensamos que o ditado popular “A pressa é inimiga da perfeição" poderia ser levado a termo quando se trata de saúde pública até mesmo nas práticas discursivas de atores políticos. Ao que parece, os discursos de uma organização mundial, que é responsável por estabelecer normas com relação às questões de saúde mundial, não são levados em consideração pelos atores públicos, notadamente o Governo, pelo menos no caso britânico.

Salienta-se que em 1996, a Organização Mundial da Saúde (OMS) decidiu desenvolver um conjunto de normas que deverão nortear a doação de medicamentos, que foram revistas em 1999. Estas normas visam promover a qualidade das doações de medicamentos, e não impedi-las, indo de encontro à necessidade urgente de estabelecer um conjunto de boas práticas para as doações, tendo presente as inúmeras situações em que estas não se adequam às necessidades do país receptor. A OMS incentivou também que as Organizações Internacionais ou Nacionais revissem, adaptassem, adotassem e implementassem um conjunto de normas para a doação de medicamentos, tendo como base aquele documento.

Em 31 de Outubro de 2000, o governo brasileiro, em sintonia com a Associação de Farmacêuticos dos Países de Língua Portuguesa (AFPLP), a partir das normatizações elaboradas pela OMS, criou um novo documento que coloca uma série de normas com relação à doação de medicamentos. Duas dessas normas são particularmente importantes ao nosso objeto de estudo (AFPLP, 2000, online):

Os receptores deverão ser informados de todas as doações de medicamentos que estiverem a ser consideradas, preparadas ou processadas; [...] As normas referidas podem não ser estritamente aplicadas, tendo em atenção a urgência das situações e as características particulares e intrínsecas dos medicamentos, desde que a sua não aplicação seja devidamente justificada, mediante consentimento prévio do receptor ou se estiverem integradas nas recomendações para situações de grande urgência da Organização das Nações Unidas. 
Essas normas nos suscitam uma questão: se as mídias de massa têm a responsabilidade de informar (ROSO; GUARESCHI, 2007), por que essas normas não são amplamente divulgadas? Por que o jornal em foco, por exemplo, prefere veicular discursos que aumentam o medo na população ao invés de divulgar elementos que possibilitem um maior controle social? ${ }^{4}$

A título de exemplo, das 291 reportagens que constituíram o corpus de análise dessa pesquisa, observa-se que nas manchetes consta um número considerável de palavras que podem incentivar o medo na população. A palavra morte(s) aparece 41 vezes, óbito e casos confirmados figuram, cada uma, em 6 manchetes, pânico em 4, epidemia consta 3 vezes e pandemia e falecimento duas vezes cada uma.

As escolhas das palavras nunca são "meras escolhas"; as elites simbólicas, que são os "políticos, jornalistas, escritores, professores, advogados, burocratas e todos os outros que tem acesso especial ao discurso público" (DIJK, 2008, p. 23), através de seus discursos manipulam as informações e a forma como estas podem ser entendidas de várias maneiras diferentes, neste caso em especial, a escrita.

Para Djik (2008), a manipulação não envolve apenas poder, mas um abuso do poder, pois as elites simbólicas influenciam os sujeitos a acreditarem ou tomarem decisões que são do interesse dos manipuladores. Para que os manipuladores possam influenciar os receptores do discurso, é preciso determinar um ambiente social onde o acesso de determinados atores, tais como jornalistas, médicos, políticos e acadêmicos, seja privilegiado. A manipulação, desenvolvida em sua forma negativa, pois produz desigualdades, realiza-se por meio do discurso em um sentido amplo, incluindo características não verbais, expressões faciais, layout de texto, imagem, dentre outros. Os receptores da manipulação muitas vezes podem ser definidos como vítimas por não possuírem recursos para resistir, detectar ou evitar a manipulação, o que pode acabar envolvendo uma ausência total ou parcial de conhecimento relevante, sem a possibilidade de elaborar um contraargumento; normas e valores fundamentais que não possam ser negados ou ignorados; emoções fortes e traumas que podem deixar as pessoas vulneráveis; e posições sócias e profissionais que induzam as pessoas a aceitar tais discursos e argumentos das elites simbólicas (DJIK, 2008).

\section{Geral | 22/07/2009 09h55min}

A empresa inglesa anunciou na terça-feira que está desenvolvendo um novo mecanismo capaz de diagnosticar a gripe suína em apenas uma hora com a mesma precisão dos exames clínicos. Baseado na tecnologia PCR (que mede a reação de polimerase em tempo real), este instrumento representa, segundo a farmacêutica, "um avanço muito promissor" que garantirá que os pacientes "sejam diagnosticados e recebam o tratamento adequado o mais rápido possível". Segundo a diretora de Pesquisa de Vacinas da OMS, Marie-Paule Kieny, é bastante improvável que a vacina esteja disponível antes do inverno no hemisfério 
norte, dado que o processo de autorização dos remédios que cumprirem os requisitos poderia se prolongar até dezembro. A GSK começou a trabalhar nela em maio, quando recebeu a cepa da gripe A (H1N1), e já tem comprometidos 195 milhões de doses com Reino Unido, França, Bélgica e Finlândia, e está em conversas com 50 países. Além disso, a companhia anunciou que doará 50 milhões de doses aos países menos desenvolvidos, para apoiar a contenção do novo vírus (GRUPO..., 22 jul. 2009, online).

Todavia, seríamos ingênuos ou por demais pessimistas se considerássemos apenas o lado negativo das ações das instituições privadas farmacêuticas. Os avanços biotecnológicos voltados para a área da saúde representam um passo muito importante não só no aumento da expectativa de vida das populações, como na qualidade de vida destas. Não podemos negar as vantagens de melhores tecnologias aplicadas à saúde, sejam elas em forma de novos medicamentos e tratamentos, ou sejam elas sob a forma de tecnologias voltadas para diagnósticos mais precisos que possibilitem intervenções em estágios iniciais de doenças. Fica claro, nas reportagens acima, a preocupação da empresa GSK em disponibilizar não somente a vacina, mas outros produtos que possam auxiliar na detecção e rápido diagnóstico.

As biotecnologias voltadas à saúde humana precisam ser desenvolvidas tendo em vista, de acordo com a Declaração de Helsinque, o maior cuidado possível com a saúde das populações, deixando desta forma as questões econômicas envolvidas em segundo plano. Porém a aplicação de vacinas nas populações de países periféricos, prática comum nas testagens, por esbarrar em leis mais "flexíveis", agora parece ter tomado proporções globais.

As experimentações com seres humanos têm suas raízes nos países africanos do final do século XIX que os colonizadores depositaram seus interesses. Para que pudessem habitar tais locais, fundações como a The London School of Tropical Medicine, foram criadas para dar suporte técnico e acadêmico para tais interesses. Infelizmente estas práticas continuaram a ser exercidas em populações economicamente desfavorecidas, como são os casos de experimentos contra a sífilis em populações negras dos EUA, conhecidos como Caso Tuskegee, e os experimentos com mulheres grávidas portadoras de HIV em países africanos (CAPONI, 2004). No ano de 2011, uma extensa investigação sobre procedimentos antiéticos foi conduzida nos EUA para apurar os danos causados por John Cluter, pesquisador do serviço de saúde pública dos EUA, que entre os anos de 1946 e 1948 contaminou deliberadamente 1300 pessoas com sífilis para averiguar a eficácia de tratamentos profiláticos (KAISER, 2011).

Para finalizar essa análise, queremos mostrar que as práticas discursivas midiáticas fazem incursão não somente em nível internacional/nacional/ regional/local. Do contexto nacional, rapidamente as palavras circulam no contexto mais próximo aos leitores. Todavia, esse movimento não parece ser tranquilo, ou assim não é apresentado pela mídia: o Rio Grande do Sul, ao mesmo tempo em 
que se situa relativamente perto do centro do país, parece não priorizado pelo Governo. É preciso que o Ministro "garanta" que vai chegar medicamento no estado; é preciso que ele "prometa" que a população daqui também será beneficiada: do país

Um contraponto da disponibilização do medicamento a qualquer região

\section{Geral | 22/07/2009 09h43min}

Chega hoje ao RS remessa do medicamento contra a gripe A Atualizada às $11 \mathrm{~h} 47 \mathrm{~min}$

José Gomes Temporão garantiu que chega nesta quarta-feira ao Rio Grande do Sul uma nova remessa do medicamento Tamiflu usado para combater a gripe A (CHEGA..., 22 jul. 2009, online).

Geral | 23/07/2009 10h56min

Remessa de Tamiflu chega ao RS

Atualizada às $12 \mathrm{~h} 04 \mathrm{~min}$

A remessa de Tamiflu prometida ontem pelo ministro da Saúde, José Gomes Temporão, chegou na madrugada desta quinta-feira ao Rio Grande do Sul (REMESSA..., 23 jul. 2009, online).

Nas três sequências discursivas abaixo, podemos perceber uma constante ênfase na necessidade de disponibilização do medicamento à maioria da população santa-mariense. A mesma notícia, escrita de modo diferente, diz "o mesmo do mesmo", ou seja, o Tamiflu, "a esperada carga" transforma-se no medicamentodesejo, desejo este coproduzido pela mídia de massa:

\section{Geral | 23/07/2009 17h13min}

Mais quatro unidades de saúde de Santa Maria terão Tamiflu

Mais quatro unidades de saúde de Santa Maria passarão a receber o Tamiflu, antiviral usado no tratamento da gripe A. O remédio já é distribuído ao Hospital Universitário de Santa Maria (Husm) e, partir de agora, chegará também aos hospitais de Caridade, da Unimed, da Guarnição (HGU) e ao PA do Patronato (FERRAZ, 23 jul. 2009, online). 
Santa Maria começa a receber mais Tamiflu

Na quinta e na sexta-feira, o Hospital de Caridade de Santa Maria e mais três hospitais - da Unimed, da Guarnição (HGU) e da Brigada Militar - e o Pronto-Atendimento (PA) do Patronato começaram a receber Tamiflu, antiviral usado no tratamento da gripe A (FERRAZ, 24 jul. 2009, online).

\section{Geral | 27/07/2009 20h51min}

Carga de Tamiflu chega a Santa Maria. Santa Maria recebeu, ainda na sexta-feira, a esperada carga de Tamiflu. O remédio é usado no tratamento da gripe A (FERRAZ, 27 jul. 2009, online).

Finalizando, deixamos clara nossa posição em relação mídias de massa e as elites simbólicas, que claramente exercem poder e influência sobre os sujeitos de acordo com os discursos que tornam públicos. Sob forma de autoridades respeitáveis e de confiança, as elites simbólicas produzem formas de agir, formas de si e as técnicas e produtos que os sujeitos devem utilizar para que a saúde da população esteja "protegida". Um tanto mais obscuro é o envolvimento das indústrias farmacêuticas, que por adquirirem vários meios de transmissão de material acadêmico, os utilizam para certificar que novos produtos sejam aceitos pela comunidade médica.

\section{CONClusão}

Vimos nesse estudo que a Influenza é uma doença conhecida pela humanidade há bastante tempo. O desenvolvimento da epidemiologia, da tecnologia e um melhor entendimento científico proporcionaram consideráveis melhoras na saúde das populações, especialmente nos dias de hoje onde os CDCs (Center for Desease Control) estão em constante alerta para "novas" epidemias, como foi o caso da cepa viral A (H1N1) 2009.

Entretanto, no momento em que o biopoder passa a ser um poder que se alastra, que se ramifica nas sociedades, a saúde deixou de ser a "vida no silêncio dos órgãos", pois ela "exige autoconsciência de ser saudável, deve ser exibida, afirmada continuamente e de forma ostentosa, constituindo um princípio fundamental de subjetividade". A busca pela saúde perfeita tornou-se a nova utopia de nossas sociedades. O papel dos meios de comunicação de massa é de importância e influência inquestionáveis pelo número crescente e cada vez mais veloz de informações que são capazes de transmitir às populações. Mas dos tempos de Gutemberg até os dias de hoje, os meios de comunicação de massa passaram por transformações de enormes proporções, transformando a forma como os sujeitos veem o mundo a partir das formas simbólicas que produzem. Contudo, os conteúdos que parecem ter maior transmissão atualmente estão ligados diretamente às formas de construção de subjetividades dos sujeitos, conteúdos 
estes vinculados não somente ao desejo material, seja ele por produtos ou formas corporais perfeitas, mas também conteúdos subjetivos que influenciam e modulam maciçamente a forma de pensar dos sujeitos, especialmente suas opiniões políticas. As atuais megacorporações midiáticas desdobram-se em vários fronts, sejam eles televisivos, rádio transmissão, mídia impressa e mídia online, afinal, é necessário que todos os tipos de público sejam atingidos, mas todas estas tecnologias convergem para um ponto em comum: a modelização dos sujeitos de acordo com os interesses das elites dominantes.

Atualmente, o jornalismo online ganha força, não pelo número de assinantes, mas pela competitividade em relação à velocidade em que as notícias são elaboradas. $\mathrm{O}$ efeito produzido por este consumo instantâneo de notícias é totalmente compatível com a proposta capitalista de consumo de subjetividades, e os sujeitos são constituídos de acordo com a oferta de produtos que lhe são oferecidos, sejam eles da espécie que forem. Não só o entretenimento, mas as notícias sobre a vida em si produzem uma experiência coletiva especificamente com este propósito, particularmente quando existe a iminência de algo negativo sobre estas. As corporações midiáticas utilizam as pesquisas acadêmicas para desenvolverem formas simbólicas que tenham força para agenciar comportamentos, influenciar movimentos sociais, promover consumo de determinados produtos, modelizando desta forma as subjetividades e alterando a percepção dos sujeitos sobre si mesmo, criando assim uma insatisfação e a possibilidade de uma busca exteriorizada que o satisfaça. Desta forma, os sujeitos acabam, muitas vezes, cindidos, de um lado um "eu realista" e, de outro, a possibilidade de um "eu criado pelo desejo" - lembrando que as mídias de massa são rápidas em (re)capturar os desejos, subjetivando o sujeito novamente, embora causando a ilusão de que o sujeito é único, singular

O evento da gripe A (H1N1) é exemplar, pois desde o início foi noticiado como algo novo, mesmo que a OMS e os pesquisadores tivessem conhecimento desta cepa viral há várias décadas. Este tipo de notícia, além de invocar o medo ligado ao desconhecimento de algo "novo", de certa forma serve para realimentar a dinâmica biopolítica, pois todas estas formas de informação que chegam ao público, com caráter biopolítico, deixam transparecer aos olhos mais atentos, as formas de normalização e disciplinarização usadas por uma sociedade de controle, que constrói subjetividades a partir de práticas diárias e comuns, porém mediante redes flexíveis e flutuantes. A biopolítica, que constitui parte fundamental da sociedade de controle, tem como objetivo envolver a vida dos sujeitos por completo, tendo como tarefa principal, administrá-la.

Durante o período da pandemia de gripe A (H1N1), não só as campanhas de vacinação estiveram muito presentes na mídia, mas vários produtos ligados à indústria farmacêutica. Atualmente, o poder do mercado farmacêutico é indiscutível, estando este sempre oscilando entre o $1^{\circ}$ e $4^{\circ}$ lugar no ranking mundial das indústrias que mais faturam no mundo, ficando atrás apenas dos grandes bancos internacionais. Estes números se tornam preocupantes quando as próprias indústrias são as patrocinadoras dos estudos e seus pesquisadores e médicos são os responsáveis pela divulgação dos resultados obtidos. 
Entretanto, a aceleração dos processos de comercialização globalizada de medicamentos nas últimas décadas, criou uma série de problemas éticos, especialmente os que afetam a Declaração de Helsinque, documento internacional elaborado pela Associação Médica Mundial, que visa regular as normativas de ética em pesquisa com seres humanos. O ponto em questão, portanto, é a forma como as testagens da medicação, e aqui falamos da vacina para a gripe A(H1N1), que foram conduzidas não considerando o tempo mínimo de segurança. A aplicação de vacinas em populações de países periféricos, prática comum nas testagens, por esbarrar em leis mais "flexíveis", agora parece ter tomado proporções globais. As campanhas de vacinação no Brasil foram responsáveis pela imunização de 81 milhões de pessoas para o caso da gripe $\mathrm{A}(\mathrm{H} 1 \mathrm{~N} 1)$, enquanto que a comercialização de medicamentos e produtos farmacêuticos foram maciços.

A questão referente à medicalização, vista pela ótica da otimização, faz com que os sujeitos busquem não somente formas hiperpreventivas para cuidar de sua saúde, mas formas de assegurar o melhor futuro possível para suas vidas biológicas. A medicalização é considerada um novo exercício de poder, onde o saber médico dita as normas, em uma distinção permanente entre o normal e o patológico. Mas embora a medicina tenha desempenhado um papel de grande importância na normatização das questões referentes ao corpo, nos dias de hoje vemos a indústria farmacêutica tomando conta da produção destes saberes e usando-os em prol de uma comercialização massiva de remédios.

Fazer um recorte da análise das reportagens justamente tomando o período crítico da pandemia (mês de julho de 2009) foi fundamental para conhecermos mais a fundo nosso objeto de pesquisa. Entretanto, gostaríamos de apontar isto como uma das limitações do estudo, pois seria interessante que fossem analisadas todas as reportagens, desde o período pré-pandêmico até o período pós-pandêmico, pois muitos nuances ficaram fora da análise. Entendemos que isto não seria possível por questões temporais, mas seria uma sugestão interessante para futuros estudos, especialmente de caráter mais longo. Outro fator interessante de ser analisado seria os diferentes discursos de diferentes jornais e mídias de massa, o que poderia apontar para possíveis identidades editoriais e maior riqueza de detalhes.

Por ser um evento relativamente novo, a bibliografia encontrada sobre a questão da pandemia limitou-se a estudos no campo das ciências da saúde, mais especificamente a achados sobre o vírus em si. Mas entendemos que optar por este tipo de abordagem, analisar um evento recente, fazer uma "cartografia do presente", é de certa forma um risco, pois muito pouco foi dito sobre o assunto. Em contrapartida, este é exatamente o lado excitante da pesquisa, pois, por muitas vezes, precisamos navegar sozinhos, descobrir e mapear os eventos presentes tendo como base as configurações genealógicas que nos trouxeram até aqui. 


\section{Notas}

O manuscrito aqui apresentado é um recorte de uma pesquisa maior que abarcou a proposta genealógica de forma bem sucedida. Entretanto, neste artigo a proposta que melhor se aplica é a cartográfica, tanto por realizar uma releitura da pesquisa original, quanto por uma questão espacial. Tamiflu ${ }^{2}$, é o nome registrado pela farmacêutica Roche. O principio ativo do medicamento é o fosfato de oseltamivir.

Escritores fantasmas.

Por controle social, entendemos "a participação da comunidade em todos os níveis de governo, tendo o direito e o dever de participar das decisões, propor as linhas de ação e os programas que considera mais importantes, controlar a qualidade e o modo como são desenvolvidos e fiscalizar a aplicação dos recursos públicos" (BRASIL, 1994).

\section{REFERÊNCIAS}

ABRÃO, J. S. Banalização da morte na cidade calada: a hespanhola em Porto Alegre, 1918. 2. ed. Porto Alegre: Edipucrs, 2009.

A POLÊMICA compra do tamiflu. Diário de Santa Maria, Santa Maria, n. 2245, 24 jul. 2009. Disponível em: <http://www.clicrbs.com.br/dsm/rs/ impressa/4,38,2591115,12782>. Acesso em: 22 jan. 2012.

ASSOCIAÇÃO DE FARMACÊUTICOS DOS PAÍSES DE LINGUA PORTUGUESA. Resolução sobre a doação de medicamentos. 2000. Disponível em: <http://www.afplp.org/xfiles/scContentDeployer_pt/docs/articleFile61.pdfs. Acesso em: 29. fev. 2012.

BAUER, M. W; GASKELL, G. Pesquisa qualitativa com texto, imagem e som: um manual prático. Petrópolis, RJ: Vozes, 2003.

BRASIL. Ministério da Saúde. Incentivo à participação popular e o controle social no SUS: textos técnicos para conselheiros de saúde. Brasília: IEC, 1994. p. 33.

CAMARGO JR., K. R. de. A economia política da produção e difusão do conhecimento biomédico. In: CAPONI, S. et al. (Org.). Medicalização da vida: ética, saúde pública e indústria farmacêutica. Palhoça: Unisul, 2010. p. 36-48.

CAPONI, S. A biopolítica da população e a experimentação com seres humanos. Ciênc. Saúde Coletiva, Rio de Janeiro, v. 9, n. 2, jun. 2004. Disponível em: $\quad<$ http://www.scielo.br/scielo.php?script=sci_arttext\&pid=S1413$81232004000200020 \& \operatorname{lng}=e n \& n r m=i s o>$. Acesso em: 18 fev. 2012.

CASTRO, E. Vocabulário de Foucault: um percurso pelos seus temas, conceitos e autores. Belo Horizonte: Autêntica, 2009. 
CHEGA hoje ao RS remessa do medicamento contra a gripe A. Diário de Santa Maria, Santa Maria, 22 jul. 2009. Disponível em: <http://www.clicrbs.com.br/ especial/rs/dsm/19,0,2589003, Chega-hoje-ao-RS-remessa-do-medicamentocontra-a-gripe-A.html>. Acesso em: 15 fev. 2012.

CORRÊA, G. ; ROSO, A. Gripe A (H1N1): um estudo bibliométrico. In: Jornada Academica Integrada, 25., 2010, Santa Maria. Anais... Santa Maria: UFSM, 2010. Disponível em: <http://portal.ufsm.br/jai2010/anais/trabalhos/ trabalho_1041271308.htm>. Acesso em: 10 fev. 2012.

CORRÊA, G. Biopolitica, Gripe A (H1N1) e Mídia: O que pode um porco? 2012. 100f. Dissertação (Mestrado em Psicologia da Saúde)-Departamento de Psicologia, Universidade Federal de Santa Maria, Santa Maria, 2012.

DIJK, T. V. Discurso e poder. São Paulo: Contexto, 2008.

DONALD H. Rumsfeld named Chairman of Gilead Sciences. Gilead - 25 years - Press Releases, 3 jan. 1997. Disponível em: <http://www.gilead.com/ pr_933190157>. Acesso em: 29 fev. 2012.

FAE, R. A genealogia em Foucault. Psicol. estud., Maringá, v. 9, n. 3, dez. 2004. Disponível em: $<$ http://www.scielo.br/scielo.php?script=sci arttext\&pid=S1413$73722004000300009 \& \operatorname{lng}=p t \& n r m=i s o>$. Acesso em: 26 out. 2010.

FERRAZ, J. Mais quatro unidades de saúde de Santa Maria terão Tamiflu. Diário de Santa Maria, Santa Maria, 23 jul. 2009. Disponível em: <http://www.clicrbs. com.br/especial/rs/dsm/19,0,2590718, Mais-quatro-unidades-de-saude-de-SantaMaria-terao-Tamiflu.html>. Acesso em: 13 out. 2011.

FERRAZ, J. Santa Maria começa a receber mais Tamiflu. Diário de Santa Maria, Santa Maria, 24 jul. 2009. Disponível em: <http://www.clicrbs.com.br/especial/ $\mathrm{rs} / \mathrm{dsm} / 1$ 9,0,2592531, Santa-Maria-comeca-a-receber-mais-Tamiflu.html>. Acesso em: 13 out. 2011.

FERRAZ, J. Carga de Tamiflu chega a Santa Maria. Diário de Santa Maria, Santa Maria, 27 jul. 2009. Disponível em: <http://www.clicrbs.com.br/especial/ rs/dsm/19,0,2596684, Carga-de-Tamiflu-chega-a-Santa-Maria.html>. Acesso em: 15 out. 2011.

FOUCAULT, M. Microfisica do Poder. Rio de Janeiro: Graal, 1995.

FOUCAULT, M. Em defesa da Sociedade. São Paulo: Martins Fontes, 2005. 
GARRAFA, V; LORENZO, C. Helsinque 2008: redução de proteção e maximização de interesses privados. In: CAPONI, S. et al. (Org.). Medicalização da vida: ética, saúde pública e indústria farmacêutica. Palhoça: Unisul, 2010. p. 21-35.

GOLONO, M. A. Variantes moleculares do vírus influenza. 2004. Dissertação (Mestrado)-Universidade de São Paulo, São Paulo, 2004.

GRIPE: governo negocia compra de vacina, diz secretário. Diário de Santa Maria, Santa Maria, 17 jul. 2009. Disponível em: <http://www.clicrbs.com.br/ especial/rs/dsm/19,0,2583725, Gripe-governo-negocia-compra-de-vacina-dizsecretario.html>. Acesso em: 12 jan. 2012.

GRUPO farmacêutico britânico começará a distribuir vacina da gripe no segundo semestre. Diário de Santa Maria, Santa Maria, 22 jul. 2009. Disponível em: $<$ http://www.clicrbs.com.br/especial/rs/dsm/19,0,2589010, Grupo-farmaceuticobritanico-comecara-a-distribuir-vacina-da-gripe-no-segundo-semestre.html>. Acesso em: 20 jan. 2012.

HENZ, A. de O. Formação como deformação: esgotamento entre Nietzsche e Deleuze. Revista Mal-estar e Subjetividade, Fortaleza, v. 9, n. 1, p. 135-159, 2009.

IMUNIZAÇÃO contra H1N1 atingiu 81 milhões de pessoas, diz Temporão. G1, São Paulo, 17 jun. 2010. Disponível em: <http://g1.globo.com/ciencia-e-saude/ noticia/2010/06/imunizacao-contra-h1n1-atingiu-81-milhoes-de-pessoas-diztemporao.html>. Acesso em: 10 fev. 2012.

KAISER, J. Panel blasts ethics, science of 1940s Guatemala studies. 2011 [online]. Science Magazine. Disponível em: <http://news.sciencemag.org/ scienceinsider/2011/08/panel-blasts-ethics-science-of.html>. Acesso em: 18. fev. 2012.

KAWAMOTO, A. H. N. Isolamento e identificação do vírus da influenza A em aves residentes e migratórias no Estado de São Paulo. Dissertação (Mestrado)Universidade de São Paulo, São Paulo, 1999.

$\mathrm{KOCH}, \mathrm{T}$. Cartographies of disease: maps, mapping and medicine. California: ESRI, 2005.

LIMA, M. Atuação psicológica coletiva: uma trajetória profissional em unidade básica de saúde. Psicologia em Estudo, Maringá, v.10, n. 3, p. 431-440, set./dez., 2005. 
LOPES, J. Vacina contra a gripe A (H1N1). Terra - Vila Equilíbrio, [S.1.], 28 jul. 2009. Disponível em: <http://vilamulher.terra.com.br/vacina-contra-a-gripe-ah1n1-11-1-60-228.html>. Acesso em: 29 fev. 2012.

MACHADO, R. Introdução: por uma genealogia do poder. In: FOUCAULT, M. Microfísica do Poder. Rio de Janeiro: Graal, 1995. p. 7-23.

MATOS, M. G. Psicologia da saúde, saúde pública e saúde internacional. Análise psicológica, Lisboa, v. 22, n. 3, p. 449-462, 2004.

OBAMA reserva US\$ 1,8 bilhão para o combate à gripe A. Diário de Santa Maria, Santa Maria, 16 jul. 2009. Disponível em: <http://www.clicrbs.com.br/ especial/rs/dsm/19,18,2582912,Obama-reserva-US-1-8-bilhao-para-o-combatea-gripe-A.html>. Acesso em: 15 dez. 2011.

OMS estima que vacina contra a gripe vai demorar meses para estar disponível. Diário de Santa Maria, Santa Maria, 15 jul. 2009. Disponível em: <http://www. clicrbs.com.br/especial/rs/dsm/19,18,2580905, OMS-estima-que-vacina-contraa-gripe-vai-demorar-meses-para-estar-disponivel.html>. Acesso em: 13 jan. 2012.

ORTEGA, F. Práticas de ascese corporal e constituição de bioidentidades. Cadernos Saúde Coletiva, Rio de Janeiro, v. 11, n. 1, p. 59-77, 2003. Disponível em: <http://www.iesc.ufrj.br/cadernos/images/csc/2003 1/artigos/2003 1\%20 FOrtega.pdf>. Acesso em: 20 ago. 2012.

PASSOS, E.; KASTRUP, V.; ESCÓSSIA, L. Pistas do método da cartografia: pesquisa-intervenção e produção de subjetividade. Porto Alegre: Sulina, 2009.

PELBART, P. P. Vida Capital: ensaios de biopolítica. São Paulo: Iluminuras, 2003.

PORTER, R. Das tripas coração: uma breve história da medicina. Rio de Janeiro: Record, 2004.

PORCIÚNCULA, B. Gripe A: mutirão contra o vírus. Diário de Santa Maria, Santa Maria, n. 2267, 19 ago. 2009. Disponível em: <http://www.clicrbs.com.br/ $\mathrm{dsm} / \mathrm{jsp} /$ default.jsp?uf=1\&local $=1 \&$ section $=38 \&$ action=noticias Impressa\&id=2 622547\&edition=12947>. Acesso em: 2. dez. 2010.

POTTER, C.W. A history of influenza. Journal of Applied Microbiology, Sheffield, n. 91, p. 572-579, 2001.

RABINOW, P. Essays on the anthropology of reason. Princenton: Princenton University, 1996. 
REMESSA de Tamiflu chega ao RS. Diário de Santa Maria, Santa Maria, 23 jul. 2009. Disponível em: <http://www.clicrbs.com.br/especial/rs/ dsm/19,0,2590540,Remessa-de-Tamiflu-chega-ao-RS.html>. Acesso em: 10 fev. 2012.

REVISTA Science e Nature avaliam publicar estudo sobre vírus mortal. Exame, [S.1.], 20 dez. 2011. Disponível em: <http://exame.abril.com.br/ciencia/noticias/ revistas-science-e-nature-avaliam-publicar-estudo-sobre-virus-mortal>. Acesso em: 20 fev. 2012.

REVISTAS avaliam como publicar estudo sobre vírus mortal de forma que detalhes não caiam em "mãos erradas". Zero Hora, [S.1.], 21 dez. 2011. Disponível em: <http://zerohora.clicrbs.com.br/rs/noticia/2011/12/revistas-avaliam-comopublicar-estudo-sobre-virus-mortal-de-forma-que-detalhes-nao-caiam-em-maoserradas-3603900.html>. Acesso em: 20 fev. 2012.

ROSE, N. The politics of life itself: biomedicine, power and subjectivity in the twenty-first century. New Jersey: Princenton University, 2007.

ROSO, A. O cotidiano no campo da saúde: ética e responsabilidade social. In VERONESE, M. V.; GUARESCHI, P. A. (Org.). Psicologia do cotidiano. Representações Sociais em ação. Petrópolis: Vozes, 2007. p. 119-146.

ROSO, A.; GUARESCHI, P. Megagrupos midiáticos e poder: construção de subjetividades narcisistas. Política \& Trabalho: Revista de Ciências Sociais, Paraíba, n. 26, p. 37-54, abr. 2007.

SÁ, J. P. O de. Determinação da Capacidade Imunogênica da Vacina de Influenza/2000 em paciente a partir de 60 anos na cidade de Maceió. 2002. Dissertação (Mestrado)-Universidade Federal de Alagoas, Alagoas, 2002.

SERRA, S. A divulgação científica de temas de saúde na mídia: análise de um impresso. 2009. Dissertação (Mestrado)-Centro Universitário Plínio Leite, Niterói, 2009

SINGER, P.; CAMPOS, O.; OLIVEIRA, E. M. de. Prevenir e curar: o controle social através dos serviços de saúde. Rio de Janeiro: Forense, 1988.

SOUZA, A. R. Avaliação da imunogenicidade e da tolerabilidade da vacina anti influenza virossomal comparada à vacina anti influenza split em pacientes com anemia falciforme. 2007. Dissertação (Mestrado)-Universidade Federal de São Paulo, São Paulo, 2007

STREY, M. N. et al. Psicologia social contemporânea: livro texto. 9. ed. Petrópolis, RJ: Vozes, 2005. 
TEIXEIRA, J. Psicologia da Saúde. Análise Psicológica. v. 22, n. 3, p. 441-448, 2004.

THOMPSON, J. B. Ideologia e cultura moderna: teoria social crítica na era dos meios de comunicação de massa. Petrópolis.Vozes, 1995.

TOLEDO JUNIOR, A. C. de C.; COSTA, J. M. F. Influenza (di freddo): quando será a próxima pandemia de gripe? In: Pragas e epidemias: histórias de doenças infecciosas. Belo Horizonte. Folium, 2006. p. 137-152.

UJVARI, S. C. A história e suas epidemias: a convivência do homem com os microorganismos. 2. ed. Rio de Janeiro: Senac Rio, 2003.

WMA Declaration of Helsinki: ethical principles for medical research involving human subjects. Oct. 2008. Disponível em: <http://www.wma.net/ en/30publications/10policies/b3/17c.pdf>. Acesso em: 21 fev. 2012.

Recebido em: 20 de março de 2012

Aceito em:03 de julho de 2012 